\title{
Quantitative Aspects of the Intestinal Yeast Flora of Swine
}

\author{
By N. VAN UDEN AND LIDIA DO CARMO SOUSA \\ Department of Microbiology, Botanical Institute, University of Lisbon, \\ Lisbon, Portugal
}

(Received 5 April 1961)

\section{SUMMARY}

Minimum numbers of viable organisms of the yeast species occurring in the digestive tract of $\mathbf{5 7}$ pigs were determined in samples from six sites in each animal (stomach, three sites in the small intestine, caecum, rectum). In 27 animals (47.4\%) Candidaslooffi was found in one or more sites in numbers ranging from less than $\mathbf{8 0 0}$ to $9,000,000$ viable organisms/g. wet sample. The trend was an increase in numbers towards the anus, with highest counts in the rectum and next highest counts in the caecum. The food eaten influenced the numbers of $C$. slooffii; food rich in starch apparently increased, while food rich in cellulose and proteins decreased, these numbers. The pig appears to constitute a suitable host for the obligate intestinal saprophyte $C$. slooffii. Other yeast species found at one or more sites in numbers above $100 / \mathrm{g}$. wet sample (in brackets the number of positive animals) were: Candida krusei (8); Saccharomyces cerevisiae (6); Pichia membranaefaciens (6); C. albicans (3); $S$. tellustris (C. bovina) (2); S. chevalieri (2); S. oleaceus (2); S. carlsbergensis (2); C. parapsilosis (2); C. tropicalis (2); S. italicus var. melibiosi (1); S. steineri (1); C. utilis (1); Torulopsis glabrata (1); not identified (1). Analysis of the counts of the three most frequent species showed an increase in the anal direction. It is concluded that $C$. krusei, $P$. membranaefaciens and $S$. cerevisiae are facultative intestinal saprophytes of swine.

\section{INTRODUCTION}

During the past few years several related yeast species, well adapted to life in the digestive tract of warm-blooded animals, have been described (Torulopsis pintolopesii, Van Uden, 1952; Candida bovina, Van Uden \& Carmo-Sousa, 1957a; Saccharomyces tellustris, Van der Walt, 1957; C. slooffi, Van Uden \& Carmo-Sousa, $1957 b$ ). Nutritional fastidiousness and a narrow temperature range with a high minimum are characteristic for this group. C. slooffi grows only between $28^{\circ}$ and $44^{\circ}$ and requires biotin, inositol, nicotinic acid, thiamine and, under certain circumstances (Kreger-van Rij, 1958), pantothenate. Originally isolated from 6 out of 252 horses (Van Uden \& Carmo-Sousa, 1957 b), C. slooffii was subsequently found also in the digestive tract of 121 out of 250 pigs (Van Uden, Carmo-Sousa \& Farinha, 1958). This high incidence (48.4\%) suggested that the pig rather than the horse might be a natural host for $C$. slooffi. In the present study we have tried to obtain quantitative information about $C$. slooffii and other yeast species which, as previous qualitative work showed (Van Uden et al. 1958), occur in the digestive tract of swine. 


\section{METHODS}

Fifty-seven swine were sampled in the abattoir of Lisbon. Samples were taken from the contents of the digestive tract at the following sites: stomach (S); small intestine at a point one-third of its total length from the pylorus $\left(\mathrm{I}_{\frac{1}{3}}\right)$; small intestine at a point two-thirds of its total length from the pylorus $\left(\mathrm{I} \frac{2}{3}\right)$; small intestine a few $\mathrm{cm}$. oral of the caecum (I $\left.\frac{3}{3}\right)$; caecum $(\mathrm{C})$; rectum $(\mathrm{R})$.

Table 1. Quantitative occurrence of Candida slooffi in the digestive tract of swine

\begin{tabular}{|c|c|c|c|c|c|c|}
\hline \multirow{3}{*}{$\begin{array}{c}\text { Serial } \\
\text { number } \\
\text { of } \\
\text { pig }\end{array}$} & \multicolumn{6}{|c|}{ Site of sample } \\
\hline & S* & $I_{\frac{1}{3}}$ & $1 \frac{2}{3}$ & I $\frac{8}{3}$ & C & $\mathbf{R}$ \\
\hline & \multicolumn{6}{|c|}{ Counts of $C$. slooffi (organisms/g. wet intestinal contents) } \\
\hline 1 & $<\mathbf{3 0 0}$ & $<300$ & $<\mathbf{3 0 0}$ & 330 & $<\mathbf{3 0 0}$ & $<\mathbf{3 0 0}$ \\
\hline $\mathbf{3}$ & 380 & 480 & $<300$ & $<3,000$ & $<3,000$ & $<\mathbf{3 0 0}$ \\
\hline 4 & 840 & $<300$ & $<300$ & 13,500 & 65,000 & 270,000 \\
\hline 6 & 360 & 420 & 370 & $<300$ & $<300$ & $<300$ \\
\hline$\gamma$ & $\mathbf{0}$ & $\mathbf{0}$ & 0 & 0 & $<300$ & 0 \\
\hline 11 & 1,030 & $<300$ & $<300$ & 4,450 & $<300$ & 440 \\
\hline 12 & $<300$ & 0 & 0 & 0 & $<\mathbf{B 0 0}$ & $<\mathbf{3 , 0 0 0}$ \\
\hline 13 & $<300$ & $<300$ & $<300$ & $<\mathbf{3 0 0}$ & $<300$ & $<300$ \\
\hline 14 & 1,230 & $\mathbf{0}$ & $<\mathbf{3 0 0}$ & $<300$ & 224,000 & $9,000,000$ \\
\hline 15 & $<300$ & $\mathbf{0}$ & 0 & $<\mathbf{3 0 0}$ & 830 & $\mathbf{1 , 3 3 0}$ \\
\hline 19 & $\mathbf{0}$ & $\mathbf{0}$ & 0 & 0 & 1,260 & 93,000 \\
\hline 20 & $\mathbf{0}$ & 0 & 0 & $\mathbf{0}$ & 0 & 330 \\
\hline 21 & $\mathbf{0}$ & $\mathbf{0}$ & 0 & 0 & 6,750 & 6,000 \\
\hline 22 & $<300$ & $<300$ & $<300$ & 420 & 139,000 & 15,500 \\
\hline 23 & $<\mathbf{3 0 0}$ & $<300$ & $<\mathbf{3 0 0}$ & $<800$ & 1,100 & 2,490 \\
\hline 24 & $<300$ & $<300$ & $<\mathbf{3 0 0}$ & 980 & 8,500 & 420 \\
\hline 25 & 44,250 & 2,130 & 2,060 & 12,200 & 329,500 & 525,000 \\
\hline 26 & 8,450 & 3,160 & $\mathbf{3 , 4 2 0}$ & 38,500 & 121,000 & 80,500 \\
\hline 31 & $<\mathbf{3 0 0}$ & $<300$ & 2,880 & 520 & 212,000 & 660,000 \\
\hline 32 & $<300$ & $<300$ & 0 & $<\mathbf{3 0 0}$ & $<\mathbf{3 0 0}$ & 470 \\
\hline 33 & $<300$ & $<300$ & $<\mathbf{3 0 0}$ & 540 & $<300$ & 0 \\
\hline 34 & 0 & 0 & 0 & 0 & $<300$ & $<\mathbf{3 0 0}$ \\
\hline 35 & 0 & 0 & 0 & $<\mathbf{3 0 0}$ & $<300$ & 0 \\
\hline 43 & $<300$ & 0 & 0 & $<300$ & 5,500 & 21,400 \\
\hline 44 & 6,770 & 14,160 & 10,650 & 4,470 & 2,640 & 720 \\
\hline 45 & 1,060 & $<300$ & 2,080 & 19,800 & 965,000 & $1,925,000$ \\
\hline 57 & 920 & 1,910 & 2,220 & 6,600 & 7,800 & 5,750 \\
\hline
\end{tabular}

$<\mathbf{3 0 0}=$ less than 80 colonies on the $1 / 10$ dilution plates.

$<3000=$ less than 30 colonies on the 1/100 dilution plates, the $1 / 10$ plates having been lost.

* $\mathrm{S}=$ Stomach; $I_{\frac{1}{3}}=$ small intestine at a point one third of its total length from the pylorus; $I \frac{2}{3}=$ small intestine at a point two thirds of its total length from the pylorus; $I \frac{s}{8}=$ small intestine $a$ few $\mathrm{cm}$. oral of the caecum; $\mathbf{C}=$ caecum; $\mathbf{R}=$ rectum.

Portions ( 1 g.) of the samples were suspended in $10 \mathrm{ml}$. sterile distilled water, shaken during $10 \mathrm{~min}$. and serial dilutions plated in $1 \mathrm{ml}$. amounts in a medium of the following composition: glucose, $2 \%(w / v)$; yeast extract (Difco), $0.5 \%(w / v)$; peptone, $1 \%(\mathrm{w} / \mathrm{v})$; agar, $2 \%(\mathrm{w} / \mathrm{v})$; penicillin, $60 \mathrm{units} / \mathrm{ml}$; streptomycin, 100 units $/ \mathrm{ml}$. After incubation at $87^{\circ}$ for $48-72 \mathrm{hr}$., the numbers of yeast colonies were recorded according to macroscopic and microscopic morphology. Representants of each type were subcultured for identification. The yeast isolates were identified by the methods of Lodder \& Kreger-van Rij(1952), Wickerham (1951) and Van Uden \& Farinha (1958). 


\section{RESULTS}

We found Candida slooffii in the digestive tract of 27 of the 57 pigs studied, an incidence of $47.4 \%$, which is near the value $48.4 \%$ found during a previous qualitative survey (van Uden et al. 1958). Thus C. slooffi appears to occur in about $50 \%$ of the digestive tracts of the pigs examined. This is an unusually high incidence for a single yeast species in the digestive tract of healthy unselected individuals of a warm-blooded host species and is inferior only to the incidences found for Saccharo-

Table 2. Yeasts other than Candida slooffi, occurring in the digestive tract of swine in numbers above 100/g. wet intestinal contents

\begin{tabular}{|c|c|c|c|c|c|c|}
\hline \multirow{2}{*}{$\begin{array}{c}\text { Serial } \\
\text { number } \\
\text { of } \\
\text { pig }\end{array}$} & \multicolumn{6}{|c|}{ Site of sample } \\
\hline & $\mathbf{S}^{*}$ & $\begin{array}{c}I_{\frac{1}{3}} \\
\text { Counts of }\end{array}$ & $\begin{array}{l}\text { I릉 } \\
\text { st (organis }\end{array}$ & $\begin{array}{l}I^{\frac{s}{a}} \\
\text { g. wet inte }\end{array}$ & $\underset{\text { nal contents }}{C}$ & $\mathbf{R}$ \\
\hline 2 & $\mathbf{0}$ & $\mathbf{0}$ & $\mathbf{0}$ & $\mathbf{0}$ & $\mathbf{0}$ & $A<800$ \\
\hline 8 & 0 & $\mathbf{0}$ & 0 & $\mathbf{H ~} \mathbf{9 , 4 0 0}$ & Н $\mathbf{7 , 4 0 0}$ & $\mathbf{H}<\mathbf{8 0 0}$ \\
\hline 8 & $\mathbf{0}$ & $\mathbf{0}$ & $\mathbf{0}$ & $\mathbf{0}$ & $\mathbf{0}$ & $\begin{array}{l}\text { A } 3,000 \\
\text { C } 4,000\end{array}$ \\
\hline 9 & $\mathbf{0}$ & $\mathbf{0}$ & $\mathbf{0}$ & $\mathbf{0}$ & $\mathbf{0}$ & $\begin{array}{r}\text { A } 5,100 \\
\text { C } 2,040\end{array}$ \\
\hline 13 & $\mathbf{0}$ & $\mathbf{0}$ & 0 & $\mathbf{0}$ & $\mathbf{0}$ & $A<\mathbf{8 0 0}$ \\
\hline 16 & $\mathbf{0}$ & $\mathbf{0}$ & $\mathbf{0}$ & $\mathbf{0}$ & $\mathbf{0}$ & $\mathbf{F}<\mathbf{8 0 0}$ \\
\hline 17 & $\begin{array}{r}\mathbf{A} t<\mathbf{3 0 0} \\
\mathbf{L}<\mathbf{8 0 0}\end{array}$ & o & $\mathbf{0}$ & $\mathbf{0}$ & $A<\mathbf{3 0 0}$ & $\begin{array}{l}\text { A } 12,100 \\
\text { F } 15,800\end{array}$ \\
\hline 19 & C 340 & $\mathrm{C}<\mathbf{3 0 0}$ & $C<\mathbf{3 0 0}$ & $\mathbf{C}<\mathbf{3 0 0}$ & $\mathbf{0}$ & $\mathbf{0}$ \\
\hline 20 & $\mathbf{A}<\mathbf{8 0 0}$ & $\mathbf{0}$ & $\mathbf{0}$ & $\begin{array}{r}\text { A 2,340 } \\
\text { M 700 }\end{array}$ & $\begin{array}{r}\text { A 2,790 } \\
\text { N } 350\end{array}$ & $\mathbf{0}$ \\
\hline 27 & A $2, \mathbf{3 1 0}$ & $\begin{array}{l}\mathbf{A}<\mathbf{3 0 0} \\
\mathbf{C}<\mathbf{3 0 0} \\
\mathbf{J}<\mathbf{3 0 0}\end{array}$ & $\begin{array}{l}\mathbf{A}<\mathbf{3 0 0} \\
\mathbf{D}<\mathbf{3 0 0}\end{array}$ & $\begin{array}{l}\mathbf{A}<\mathbf{3 0 0} \\
\mathbf{G}<\mathbf{3 0 0} \\
\mathbf{D} \mathbf{3 3 0}\end{array}$ & $A<\mathbf{3 0 0}$ & $\begin{array}{l}\text { C } 2,160 \\
B<300 \\
E<300\end{array}$ \\
\hline $\mathbf{3 4}$ & D 330 & $\mathrm{D}<\mathbf{3 0 0}$ & $\mathrm{D}<\mathbf{3 0 0}$ & $\mathrm{D}<\mathbf{3 0 0}$ & $\mathbf{0}$ & $\begin{array}{l}\mathbf{C}<\mathbf{3 0 0} \\
\mathrm{B}<\mathbf{3 0 0}\end{array}$ \\
\hline 35 & $A<800$ & $\mathbf{0}$ & $\mathbf{0}$ & $B<\mathbf{3 0 0}$ & $\mathrm{B}<\mathbf{3 0 0}$ & J 12,000 \\
\hline 39 & $\mathbf{0}$ & $\mathbf{0}$ & $\mathbf{0}$ & $\mathbf{0}$ & $\mathbf{0}$ & E $\mathbf{5 2 , 5 0 0}$ \\
\hline 40 & B 20,300 & B 450 & B 3,300 & B 4,500 & B 300,000 & B $1,855,000$ \\
\hline 41 & $\mathbf{0}$ & $\mathbf{0}$ & $\mathbf{0}$ & $\mathbf{0}$ & $\mathbf{0}$ & $\begin{array}{r}\mathbf{B}<\mathbf{3 0 0} \\
\mathbf{C}<\mathbf{3 0 0} \\
\mathbf{I}<\mathbf{3 0 0} \\
\mathbf{P}<\mathbf{3 0 0}\end{array}$ \\
\hline 42 & В $\mathbf{3 0 , 0 0 0}$ & $\mathbf{0}$ & B 30,000 & B $\mathbf{3 0 , 0 0 0}$ & B 435,000 & $\begin{array}{r}\text { B 2,148,000 } \\
\text { R 201,000 }\end{array}$ \\
\hline 44 & D 8,270 & $\begin{array}{l}\text { D } 7,720 \\
\text { G } \mathbf{8 , 8 6 0}\end{array}$ & $\mathbf{0}$ & D 7,270 & D 1,760 & $\begin{array}{l}\mathrm{D}<\mathbf{8 0 0} \\
\mathbf{Q}<\mathbf{3 0 0}\end{array}$ \\
\hline 47 & 0 & o & o & 0 & o & P 16,500 \\
\hline
\end{tabular}

* $\mathbf{S}=$ Stomach; $I \frac{1}{3}=$ small intestine at a point one-third of its total length from the pylorus; $I$; small intestine at a point two-thirds of its total length from the pylorus; $I \frac{s}{3}=$ small intestine a few cm. oral of the caecum; $\mathbf{C}=$ caecum; $\mathbf{R}=$ rectum.

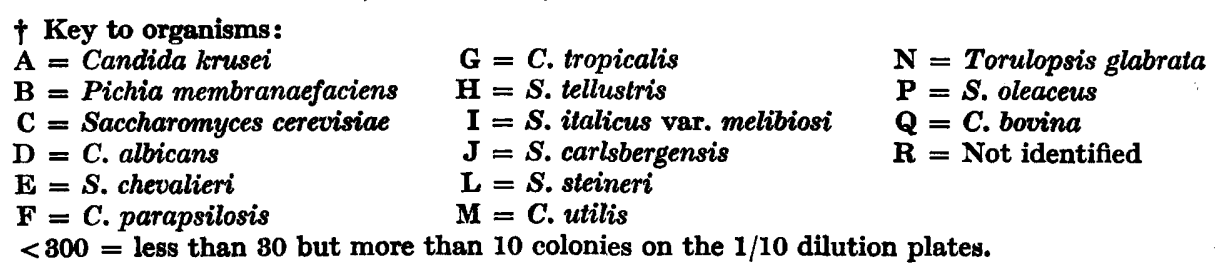


mycopsis guttulata in rabbits (Shifrine \& Phaff, 1958) and Torulopsis pintolopesii in mice and rats (Mackinnon, 1959). This indicates a high suitability of swine as hosts for C. slooffii.

The minimum numbers of viable organisms of Candida slooffi/g. wet intestinal contents differed from animal to animal and from site to site in the same animal, between extremes of $9,000,000$ and less than 800 (Table 1). The counts of $C$. slooffi in the digestive tract showed a trend to increase towards the anus; the second highest counts were most frequent in caecal contents, the highest counts in rectal contents (Fig. 1). This shows that $C$. slooffi multiplies while moving through the digestive tract. The $C$. slooffii population reaches its highest density when leaving the digestive tract. This implies some drainage at the pig's expense of the growth factors on which C. slooffii is dependent (see introduction).

Table 3. Incidences in srwine digestive tract of yeast species other than Candida slooffi, showing more than 100 organisms/g. wet intestinal contents, compared with the incidences of yeast species isolated during a qualitative survey

The figures give percentage of animals which were positive.

\begin{tabular}{|c|c|c|c|}
\hline Quantitative survey & $(\%)$ & Qualitative survey* & $(\%)$ \\
\hline Candida krusei & $14 \cdot 0$ & C. krusei & $14 \cdot 8$ \\
\hline Saccharomyces cerevisiae & $10 \cdot 5$ & S. tellustris (C. bovina) & $14 \cdot 0$ \\
\hline Pichia membranaefaciens & 10.5 & C. albicans & $\mathbf{9 \cdot 2}$ \\
\hline C. albicans & $5 \cdot 3$ & S. cerevisiae & $8 \cdot 8$ \\
\hline S. tellustris (C. bovina) & $\mathbf{3 \cdot 5}$ & P. membranaefaciens (C. mycoderma) & $7 \cdot 6$ \\
\hline S. chevalieri & $\mathbf{3 \cdot 5}$ & C. tropicalis & $6 \cdot 0$ \\
\hline S. oleaceus & 3.5 & T. glabrata & $\mathbf{3 \cdot 2}$ \\
\hline S. carlsbergensis & $\mathbf{8 \cdot 5}$ & S. italicus & 0.8 \\
\hline C. parapsilosis & $\mathbf{3 \cdot 5}$ & C. parapsilosis & 0.8 \\
\hline C. tropicalis & $\mathbf{8 \cdot 5}$ & S. carlsbergensis & 0.4 \\
\hline S. italicus var. melibiosi & 1.8 & P. farinosa & 0.4 \\
\hline S. steineri & 1.8 & Hansenula angusta & 0.4 \\
\hline C. ulilis & 1.8 & T. famata & 0.4 \\
\hline Torulopsis glabrata & 1.8 & Trichosporon cutaneum & 0.4 \\
\hline Not identified & 1.8 & & \\
\hline
\end{tabular}

Though swine are suitable hosts for Candida slooffi, not every animal harbours this yeast at a given time and the numbers or organisms in the positive animals may vary greatly. One factor which interferes with individual host suitability seems to be the diet fed. From our not wholly complete records about the diets of the pigs sampled, the following can be said: (1) most pigs which did not reveal the presence of $C$. slooffi had been kept on a green food diet; (2) most pigs with low numbers of $C$, slooffi $i$ throughout the digestive tract had been on a mixed diet, including kitchen refuse; (3) most pigs with high counts for $C$. slooffi had been kept on a grain diet, chiefly maize. These observations suggest that food rich in cellulose (1) and proteins (2) had an adverse effect on intestinal C. slooffi, and food rich in starch (8) a stimulatory effect.

In 18 of the 57 pigs, yeast species other than Candida slooffii were found in numbers exceeding 100 viable organisms/g. intestinal contents (Table 2). Most of these species had also been found in an earlier qualitative survey (Table 8). C. krusei, 


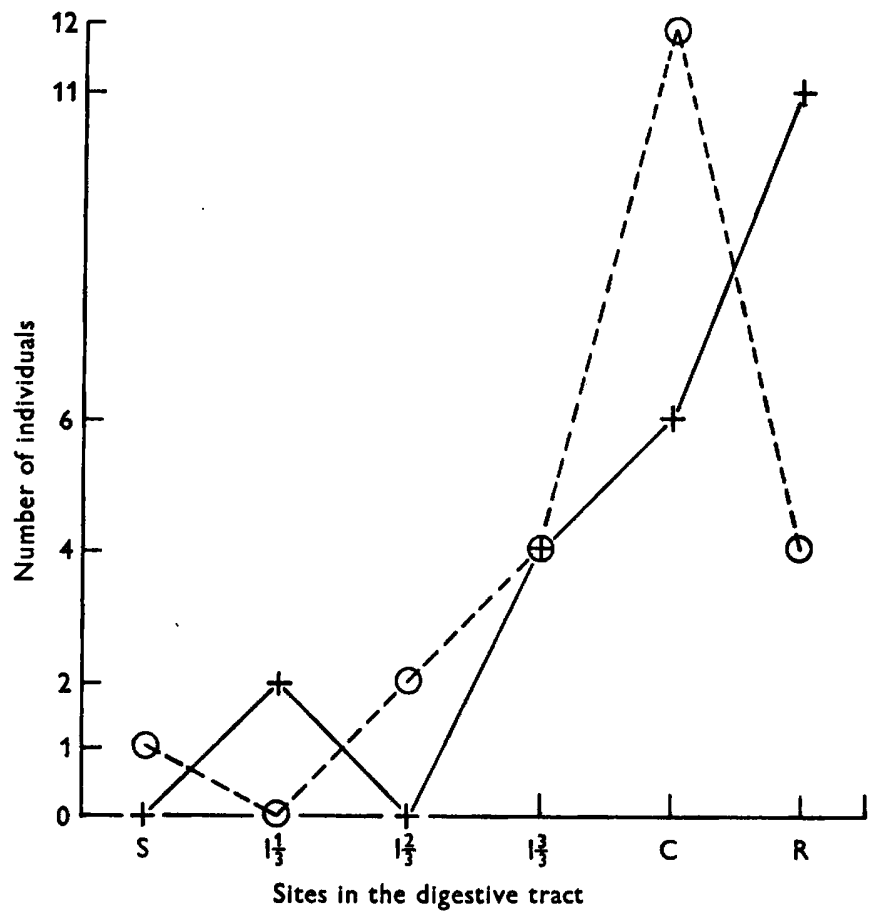

Fig. 1. Frequency of highest and second highest counts for Candida sloofii in six sites of the digestive tract of 57 swine. $S=$ stomach; $I_{\frac{1}{3}}=$ small intestine at a point onethird of its total length from the pylorus; $I \frac{2}{3}=$ small intestine at a point two-thirds of its total length from the pylorus; $I \frac{s}{3}=$ small intestine a few $\mathrm{cm}$. oral of the caecum; $\mathbf{C}=$ caecum; $\mathbf{R}=$ rectum. $+=$ highest counts; $O=$ second highest counts.

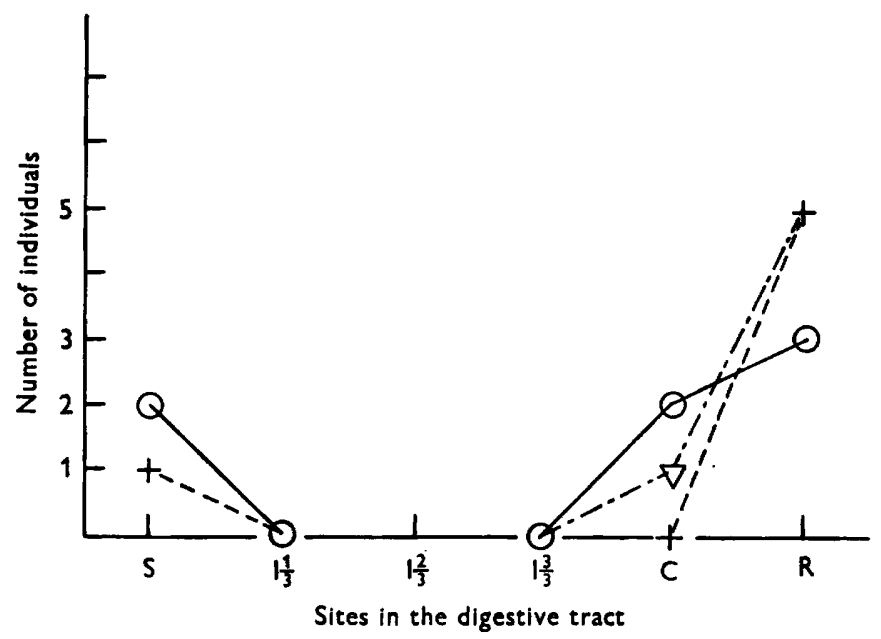

Fig. 2. Frequency of highest counts for Candida krusei, Saccharomyces cerevisiae and Pichia membranaefaciens in six sites of the digestive tract of 57 swine: $S=$ stomach; $I_{f}=$ small intestine at a point one-third of its total length from the pylorus; $I \frac{s}{2}=$ small intestine at a point two thirds of its total length from the pylorus; $I \frac{5}{a}=$ small intestine a few cm. oral of the caecum; $\mathbf{C}=$ caecum; $\mathbf{R}=$ rectum. $O=$ Candida krusei; $+=$ Saccharomyces cerevisiae; $\nabla=$ Pichia membranaefaciens. 
Pichia membranaefaciens and Saccharomyces cerevisiae were the most frequent species with numbers ranging from more than 100 to more than 2,000,000 organisms/g. wet intestinal contents. These three species are widespread in nature. When they occur in the digestive tract they are therefore either passers-by or facultative saprophytes. The latter possibility is the case in the pig's digestive tract as is shown in Fig. 2; the highest counts for those three species were more frequent in the rectum than in other parts of the digestive tract, which shows their capacity of multiplication in this environment. S. tellustris (C. bovina), C. albicans and Torulopsis glabrata, well known as obligate saprophytes of warm-blooded animals, do not seem to be particularly well adapted to healthy pigs, as is suggested by their low incidences and low cell numbers (Table 2).

This work was subsidized by the Direcção Geral dos Serviços Pecuários, Secretariat of Agriculture, Lisbon, and by the Instituto de Alta Cultura, Lisbon.

\section{REFERENCES}

KREGer-VaN RIJ, N. J. W. (1958). The relationship between Saccharomyces tellustris and Candida bovina. Antonie van Leeurvenhoek J. Microbiol. Serol. 24, 137.

LoDDER, J. \& KReger-VAN RIJ, N. J. W. (1952). The Yeasts. Amsterdam: North Holland Publishing Co.

Mackinnon, J. E. (1959). Levedura del raton y de la rata. Arch. Soc. Biol. Montevideo, 24, 48.

Shifrine, M. \& Phaff, H. J. (1958). On the isolation, ecology and taxonomy of Saccharomycopsis guttulata. Antonie van Leetvenhoek J. Microbiol. Serol. 24, 193.

van Uden, N. (1952). Zur Kenntnis von Torulopsis pintolopesii sp.nov. Arch. Microbiol. $17,199$.

van Uden, N. \& Carmo Sousa, L. Do (1957a). Yeasts from the bovine caecum. J. gen. Microbiol. 16, 385.

van Uden, N. \& Carmo Sousa, L. Do (1957b). Candida slooffii nov.sp., a thermophilic and vitamin deficient yeast from the equine intestinal tract. Port. Acta Biol. (A), 5, 7.

VAN UDEN, N. \& FARINHA, M. (1958). On the significance of temperature relations and vitamin deficiency patterns in the delimitation of yeast species. Port. Acta Biol. (B), 6, 161.

van Uden, N., Carmo Sousa, L. Do \& Farinha, M. (1958). On the intestinal yeast flora of horses, sheep, goats and swine. J. gen. Microbiol. 19, 435.

van DER WALT, J. P. (1957). Three new sporogenous yeasts from soil. Antonie van Leeurvenhoek J. Microbiol. Serol. 23, 23.

WickerhaM, L. J. (1951). Taxonomy of yeasts. Tech. Bull. U.S. Dep. Agric. no. 1029. 